Article

\title{
Challenging Standard Concepts of 'Humane' Care through Relational Auto-Ethnography
}

\author{
Alistair Niemeijer * and Merel Visse \\ Ethics of Care, University of Humanistic Studies, 3512 HB Utrecht, The Netherlands; E-Mails: a.niemeijer@uvh.nl (A.N.), \\ merel.visse@uvh.nl (M.V.) \\ * Corresponding author
}

Submitted: 24 June 2016 | Accepted: 7 September 2016 | Published: 10 November 2016

\begin{abstract}
What is deemed 'good' or 'humane' care often seems to be underpinned by a standard ideal of an able-bodied, autonomous human being, which not only underlies those 'social and professional structures within which narratives and decisions regarding various impairments are held' (Ho, 2008), but also co-shapes these structures. This paper aims to explore how a relational form of auto-ethnography can promote good care. Rather than being based on and focused toward this standard ideal, it challenges 'humanity' by showing how illness narratives, public discourse, and policy are framed by ethical questions. It illustrates how normative ideas dictate policy and public discourse. It critically questions this constitutive power by shifting attention to the lived experiences of people with chronic illness and disability. By highlighting and reflecting together on the first author's life with a chronic illness and his son's disability, and thereby framing the narrative, it will be argued that, in order to improve care practices, personal illness and disability narratives and the way they interlock with public narrative and auto-ethnographic methodologies should be investigated.
\end{abstract}

\section{Keywords}

auto-ethnography; care ethics; disability; chronic illness; humane care

\section{Issue}

This article is part of the issue "Humanity as a Contested Concept: Relations between Disability and 'Being Human'”, edited by Paul van Trigt (Leiden University, The Netherlands), Alice Schippers (Disability Studies in Nederland, The Netherlands), and Jacqueline Kool (Disability Studies in Nederland, The Netherlands).

(C) 2016 by the authors; licensee Cogitatio (Lisbon, Portugal). This article is licensed under a Creative Commons Attribution 4.0 International License (CC BY).

From: Alistair Niemeijer

Sent: Friday 18 October 2014 14:12

To: Merel Visse

Subject: Re: Article auto-ethnography

Dear Merel,

I just wanted to tell you that I have finally read the auto-ethnographic article you co-wrote with Truus, and it made a huge impression on me. On the one hand because it is an account of a fellow researcher, and, as you have pointed out before, not everyone working in academia is willing to tell their own story. On the other hand it is so unique because I have come across so few of these articles before. So many things that were described struck a chord with me, such as the cyclical aspect of having a chronic illness (rather than a linear one) and doing lots of silly things just to 'belong' (remember last conference when I had to sleep on the floor of an empty classroom just to get some rest). 
I remember that when I first became ill I had given myself the personal assignment to also create something from this, or to cite the article: 'I'd better do something with it', but in my case also something 'good', whatever that may be. Now, inspired by your article, and spurred on by our other colleagues, I hope to also contribute something, and if you think this is a good idea, I would very much like to involve you (and your expertise) in this. So thanks again for sending me the article, it is very encouraging for me to see that such a unique perspective is actually valued as such.

Best,

Alistair

\section{Introduction}

This article illustrates and discusses how a relational form of auto-ethnography might promote good care by highlighting the everyday realities of living with a chronic illness or disability. As care ethicists with a strong affinity with Disability Studies, we are always interested in promoting good care and therefore ask whether a relational auto-ethnography on living with illness and disability might contribute towards that aim.

In general, auto-ethnography might be understood as an approach involving autobiography, self-observation, and reflexive investigation in the context of ethnographic inquiry, thereby connecting the personal to the public (Ellis, 2004; Maréchal, 2010; Visse \& Niemeijer, 2016). It differs from ethnography specifically in the foregrounding of the researcher's own (private) experiences and subjectivity, as opposed to attempting to limit these. Indeed, as Denzin (2014) has pointed out, any qualitative inquiry which is aimed at social justice (and a more caring society) should 'develop a methodology that allows us to examine how the private troubles of individuals are connected to public issues and to public responses to these troubles' (Denzin, 2014, pp. 5-6). However, as Ellingson and Ellis (2008) have indicated, 'the meanings and applications of auto-ethnography have evolved in a manner that makes precise definition difficult' (p. 449). In this case, the so-called 'private troubles' are those of the first author. The above email sent by the first author to the second author served as a starting point for a mutual, relational endeavor, as opposed to a solitary, noncultural (thus autobiographic) undertaking. Both authors are care ethical scholars working at a university department. The first author lives both with a chronic illness and a young son with Down's Syndrome in, what Arthur Frank has so aptly called, a remission society, where patients are 'effectively well, but could never be considered cured' (Frank, 2005, p. 163).

According to Pols (2013), when care in society 'chronifies', as might be the case in chronic illness and disability, there is a need for new knowledge and new values to re-orient care. Instead of viewing care and treatment as one-time events provided by professionals or short interruptions in the life of one person that ought to be self-managed, Pols argues that it becomes important to look at how care practices are shaped over time and how these might help people live with their illness and/or disability (Pols, 2013).
The emphasis in care ethics lies in the study of everyday care practices in the context of societies, rather than trying to encompass the totality of (a) society. By eliciting critical events of daily routines of people living with disease or disability and the everyday aspirations of caregivers, these studies can inform us about why and how what might be conceived of as 'good' emerges, and under what conditions (cf. Klaver, van Elst, \& Baart, 2014; Pols, 2013). This entails that the accounts and the representations of what currently might be depicted as 'humane' and 'caring' have to be seen against a background of sound (historical) anthropology describing everyday life. Rather than viewing care as 'humane', we deal with practices in which '(hu)man(e)' is produced relationally (Goodley \& Runswick-Cole, 2016). Research geared towards the humanization of practices should thus not be simply restricted to theoretical reflection and clarification but should also aspire to make a practical contribution to fostering specific humanization as both an outcome and a process simultaneously (Visse, 2012).

As these social practices change rapidly under the influence of current (political and socio-economic) realities, this means (re-)interpreting these practices through repeated and meticulous empirical research and connecting emerging insights with theory. Consequently, as we aim to show in this paper, this should be done by mapping and comparing ways of living in such a manner that it leads to knowledge about what it means to be human, which is not only relevant to a particular person, but which might also be useful for what happens to others elsewhere. Ultimately we will argue that the 'classic humanist trope' (Goodley \& Runswick-Cole, 2016) of a lone, fully functioning able-bodied thinking subject no longer works as an image of what it means to be (a caring and cared for) human, and is therefore in need of other, richer concepts in order to improve practices of care for people with chronic disease and disability.

\section{Contesting an Ableist Ideology}

What is deemed 'humane' invariably depends on the historical and cultural dynamics of meanings (of life) and constantly shifting articulations of 'humane' in particular settings. This is particularly pertinent in (institutionalized) care, as neo-liberalist policies have urged more and more people living with illness and disability to take control over their own health and life and act accordingly, 
as independent users and consumers (Teunissen, Visse, \& Abma, 2015). Simultaneously, in recent decades, intertwining ideas of self-determination and well-being have received tremendous support in the disability movement and in bioethics, guaranteeing people with disabilities a voice and protecting them against any patronizing and unwanted paternalism. However, less attention has been paid to the ableist ideology which seems to underpin these ideas, including the social structures which influence any form of decision-making (Ho, 2008).

Moreover, an ableist form of autonomy is often only upheld as a form of negative freedom, i.e. the absence of (extraneous) interference or coercion. It contrasts as such with the (ethical) motives of care professionals to involve or engage themselves with others and it has little room for the value of concrete practices and particular relationships (Hertogh, 2010) and still less for sensitivity to 'the complex conditions that actually support the unique identity of those individuals needing ... care' (Agich, 2003, p. 134). Consequently such a negative conception of autonomy is hardly useful in formulating an ethics of (chronic) care and reflects the 'idealized paradigm of choice or decision-making dominating ethical analysis' (Agich, 2003, p. 165).

To seriously consider how somebody experiences life, what challenges he or she encounters and, based on this, to think about what it means to care well for people with (chronic) illness and/or disability, implies approaching 'care' from both a more person-centered and relational perspective. Nevertheless, modern care policies seem to presuppose an 'ideal(ized) client/patient', namely an able-minded, autonomous agent who seeks independence and appropriates care services as such. To be able-bodied and able-minded is indeed often the ideal on which meanings of a good life are constructed (Hertogh, 2010; Ho, 2008). These meanings underlie not only 'the social and professional structures within which discussions and decisions regarding various impairments are held' (Ho, 2008, p. 198) but also the aims and 'consumption' of (institutionalized) care services that coshape these structures. As Goodley and Runswick-Cole (2016) suggest: 'many disabled people have been denied the opportunity to occupy the position of the modernist humanistic subject: bounded, rational, capable, responsible and competent. Being recognized as having these ideals is understandably a big deal (it is a mark of being considered human after all).' However, this raises an important epistemological question: how can people with chronic illness or disability actually be viewed as (more) human if this concept is underpinned by a deficient yet pervasive, 'ableist' humanistic ideal?

Rather than simply looking for what is 'just' or what is 'humane' in a given practice, we would like to argue here that it might be more helpful to shift the focus to what matters to the people whose positions (or in fact, human-ness) are contested. In other words, what people care for and about as evaluative beings (Sayer, 2011). But how can this evaluative knowledge be accessed? Auto- ethnography, as an epistemology and methodological approach, might be one possibility.

\section{Accessing the Particular}

According to Neumann, auto-ethnographic texts democratize the representational sphere of culture, by locating the particular experiences of individuals in tension with dominant expressions of discursive power (Neumann, 1996). Hence, auto-ethnography has a political dimension: it has the potential to reclaim authentic voices which are often less visible (or audible) than those of people deemed 'more able', by introducing (vulnerable) insiders' perspectives on experiencing living with illness and disability. What people care for and about, what they are responsive to, is often not well defined but emerges from a complex sociopolitical process of relating to each other in everyday situations. We can only thoroughly understand the particularities of these situations and the people involved by looking closely at what happens in particular situations and how people experience these occurrences. In order to be able to distinguish an occurrence and an 'event' (or epiphany, in line with Denzin), we need to become familiar with the setting and embody an insider's perspective. As an outsider, we are not always able to determine what events and situations mean; we do not know whether we can actually label any occurrence as an event. Thus, we would like to propose here a radical emphasis on the particular. However, in our view, placing the 'particular' at the center should also involve recognizing the sociopolitical and relational nature of knowledge of 'the particular'.

At the same time, we view auto-ethnography as a mutual endeavor: an epistemological approach and a methodology that allows us to examine dialogically the 'radically particular' (Visse \& Niemeijer, 2016). It is only through dialogue (not necessarily verbal conversation, but dialogue in the broad sense of an encounter) that insiders' knowledge and experiences of persons can become known. Through dialogue, tacit understandings become visible and can be reflected on together.

Care ethics has always emphasized the importance of voice and dialogue that enables an inclusive (deliberative and responsive) approach. Despite this attention, there is still a lack of in-depth understanding of how to hear particular voices, perspectives and experiences. It is important to acknowledge here that 'voice' is not a panacea. Equally important (one might say requisite) to expression of voice is an audience: voices have to reach those who are willing to listen and reflect on what they are hearing. Consider for example, the following transcript of a recorded reflection by the first author (who shares his voice with a later potential listener, in this case the second author):

'I feel really tired today, even though I have had a relatively relaxed weekend. But it is as if I'm constantly short of breath. It started this morning, something 
didn't feel right, and yes, then you immediately start to worry whether this is a sign that you have been doing too much, or that things are worsening again, because I tend to always interpret these things always in terms of progression or exacerbation. And that can be tiring in itself, because sometimes you just want to be tired without there being a dimension of 'this will have these and those consequences' etcetera. Not just for me, but also my family, friends and even colleagues. This is especially difficult with regard to my work-I am actually recording this at work this moment, alone in my office-because you really want to remain productive, effective even and not burden others with your illness. Recording this at least gives me a sense that I am sort of spending my time worthwhile, but when I am tired like this, it is so difficult to work effectively. You tend to linger with certain things, and of course you actually do less, but you're also somewhat irritated with yourself that you're doing so little, showing so little productivity. But, funnily enough, at the same time, you tend to also be satisfied more quickly with doing anything at all, even if it doesn't count as being productive. Now it is always difficult as an academic to pinpoint exactly the productivity of all that I do. Is this recording actually productive? But of course I have set tasks, such as correcting papers, responding to students' emails, that are waiting and I can't seem to come round to today as I have so little energy.'

The above example gives us an insight into the immediate and personal thoughts of the first author, who mentions the fact that he is tired, but also reflects on how this fatigue is reinforced by feelings of not knowing how to interpret it and on what it means for his productivity as a professional. In a certain sense, one might say that he has internalized an all-too familiar discourse which has been prominent in modern Western society and requires people to manage their lives independently and successfully and act as if their lives were an open project (Giddens, 1991). It is also interwoven into policies that are designed top down, focused on efficiency and productivity, and which lack consultation or deliberation with the people they concern. The above example shows that this individualization discourse affects the perspectives and expectations of all citizens, professionals and institutions, including those with a chronic illness and/or disability. As a result, people find themselves in ambiguous practices dominated by policy perspectives aimed at individualization, which may ultimately lead to a more 'dark and political' side of care (O'Toole \& Meier, 2003; Visse, 2012).

\section{Relational Auto-Ethnography}

At this point it is important to reiterate that we do not view auto-ethnography solely as an approach to gain access to insiders' knowledge and experience (i.e. 'voice'), but as a necessary space in which to enter a dialogical learning process regarding good care that constitutes and articulates voices simultaneously. Auto-ethnography fosters learning processes of self-understanding. For example, ethno-graphing illness entails actively interpreting (mapping out) the meaning of illness in cultural contexts. This interpretive 'act' can be seen as an act of caring for the self by being attentive to one's own needs and preferences, and responding to increased awareness of those needs. However, a relational auto-ethnography would also entail caring for others, and being open to others' perspectives in the construction of one's lifeworld. In line with dialogical hermeneutics, the self and the other are not separated, but closely engaged in a dialogical process where the subject matter unfolds in the dialogue (Gadamer, 1975, p. 396). In situations where self and other are related, the process of self-understanding can be seen as constitutive of the dialogue and vice versa.

Sharing experiences with disability or illness in the context of auto-ethnography occurs between people who are seen as interdependent beings. Only one person articulating experiences while the other person 'captures' or asks questions does not foster a humane practice and might even lead to what Guba and Lincoln (1989) have dubbed 'malconstructions' of people's perspectives. For instance, social activist and critical thinker bell hooks (Gloria Jean Watkins) has questioned the academic's engagement with the Other, and argued that, to truly engage, the academic would have to remove him or herself as 'the expert' at the center of the relation, in order to avoid 'colonization' of the Other's own story:

'[There is] no need to hear your voice, when I can talk about you better than you can speak about yourself. No need to hear your voice. Only tell me about your pain. I want to know your story. And then I will tell it back to you in a new way. Tell it back to you in such a way that it has become mine, my own. Re-writing you, I write myself anew. I am still author, authority. I am still [the] colonizer, the speaking subject, and you are now at the center of my talk.' (Hooks, 1990, p. 43)

Accordingly, how people respond to and engage with one another will ideally always occur from a stance of openness to genuinely understanding the other (Gadamer, 1975 , p. 390), despite possible conflicts or disagreements. Only in this case can auto-ethnography be seen as a praxis of care (Visse \& Niemeijer, 2016). According to Gadamer, the process of accessing and widening one's own point of view is always dialogical. Through dialogue, people articulate, explore, interpret, 'test' and transform their experiences. This does not happen intentionally, but occurs in and through conversation and encounter. This means we cannot control or influence understanding deliberately. We can however, be open to understanding, by listening to the other and being prepared to move into a shared dimension of meaning: 'The prejudices of the individual, far more than his judgments, constitute the historical reality of his being' (Gadamer, 1975 , p. 245). 
In the context of care, personal meanings, empathic understanding, suspension of judgment, and apprehending the other's reality as a possibility are necessary for auto-ethnography to foster care (Noddings, 1984). For instance, the second author of the article tries to make sense of the experiences of the first author, writing to him the following email:

From: Merel Visse

Sent: Saturday 3 January 2015 16:15

To: Alistair Niemeijer

Subject: after having read your transcripts.

Dear Alistair,

Intrigued I read your transcripts $(1 \mathrm{t} / \mathrm{m} 6)$. A few times I lay them aside and picked them up again. Finally today I could see a recurring theme through all of it.... Of course, I am writing this with a large disclaimer: this is my interpretation or lens. So please tell me if this does not resonate with you.

When I was reading I was constantly asking myself: who is telling the story? This is Alistair, he is writing in the first person. But then: Yes, but which Alistair? It was as if I could read different selves, or voices from the same one Alistair. Often you start the sentence with ' $I$ '....and then a personal experience is recounted. But then, and you also mention this, you start to evaluate these experiences. It is as if you're an ongoing evaluator.

So I started to wonder: who is this 'self' which is evaluating, or which voice is actually speaking? At times you also write about different positions of this 'self', although these are not always clearly present, but at times you seem to transcend all of these 'selves', reflecting on a certain meta level on how you are telling your story. When you are recounting, you often tend to position yourself (explicitly) in relation to others. Now from a care ethical perspective this is not strange, but you seem to do this very explicitly. Whether you are not 'a burden', or 'a bore', or whether you can 'fulfill certain expectations' etcetera. At the same time you have also mentioned loneliness and intimacy (of which the latter actually seems to point to a warm relation with yourself).

To sum up: perhaps it would be useful to distinguish between these 'multiple selves', each with their own positions (in time, but also with regard to others) and the conflicts between these positions, including the relations and meanings that are involved?

One of the reasons this might be useful is that it could lead to a (care ethical) redefining of for instance 'self-management'....because, as you have shown, self-management would then not make any sense, because there is not simply 1 self.

Let me know what you think!

Best,

Merel

An important insight that comes to the fore here is the fact that people with a chronic illness are not simply patients, but also partners, colleagues, consumers, and soliloquists. Once they make a decision concerning treatment or care, we should ask: which self (if not a combination of multiple selves and/or multiple discourses) is making this decision? And how does it contrast with what the other self would prefer? This is in strong contrast with the dominant conceptualization of man and society stemming from liberal political theory, which projects people as individuals who are independent and selfsufficient, and portrays the ideal relationship in more or less contractual terms, where people act as equal citizens within a public realm (Agich, 2003; Hertogh, 2010;
Nussbaum, 2006; Tronto, 1993). It is highly questionable whether vulnerable people with an illness or disability, if indeed any of us, meet this idealized assumption of being totally independent and self-sufficient, or whether this is not simply 'a mere fiction' (Kittay, 2011, p. 51). Indeed, should being human be seen not as singular, but rather as polyvocal? If this is the case which self is ultimately responsible? And which self has priority in making 'informed' decisions?

Nevertheless, rational choice and independence is still the predominant approach in dealing with normative issues in care and this has several important implications for people with chronic illness and disability. Firstly, this emphasis on independence leads to a discourse in 
which 'the language of rights eclipses other ethical language', as care is primarily thought of in terms of problems which can be regulated and dealt with by establishing rights (Agich, 2003). However, it may also create a backlash against dependence of any sort, with those in need of care susceptible to the pejorative meanings associated with illness, dependence or disability (Agich, 2003; Hertogh, 2010). This can occur despite the fact that there is a growing interest in patient experiences and patient stories, as the following fragment of a recorded conversation between the authors examines:

Alistair: what I seem to miss in those patient stories, particularly of those living with inflammatory bowel disease (IBD)-and there is plenty of material, patient blogs and vlogs, several books etc.-is that it often stops at the toilet door. You can never look behind the door. The way experiences are told are in a sort of remote way, sometimes even in third person. So if you tell people more graphic experiences about pooh and diarrhea, which is an integral part of this disease...well then.

Merel: you open up the conversation, because all conventions suggest 'one shouldn't talk about these things'...?

Alistair: Exactly, and in public discourse certain diseases seem to be more interesting or more 'sexy' to talk about, such as certain forms of cancer tend to be in the media more than other forms, which is not always dependent on the number of people with this illness. For instance, what I find quite remarkable is that my son's disability is much more well-known than my own disease. When I say that my son has Down's Syndrome, I don't really have to explain myself. Yes, of course there are all these misconceived notions and ideas about this disability, but most people seem to have at least a basic idea of what it involves. Whereas when I mention I have Crohn's disease, half of the time people haven't even heard of it. Even though the IBD population is much larger! I think this might be related to the somewhat embarrassing aspect of this disease, plus the non-visible aspect. It is kind of an elusive or incomprehensible type of illness. In my experience, many people are always very surprised when they learn I have this illness. I remember when we went to that conference in Stuttgart, when I was still in the midst of a flare up and at some point somebody asked me whether I had the 'flu...I don't mind it that much, and kind of understand it, because if you don't see it, then, well...I realize that when as colleagues you still receive coherent, 'semi-intelligent' contributions from me, that this doesn't match up with somebody who is very ill at that particular moment, maybe the expectation of people is that my contribution would be something less coherent. That in a sense you're only ill when you're also ill on an intellectual level, even though you know from your work with Truus that this doesn't really matter.
Merel: So you are giving the illness a face? Or actually several faces, including the public face, the intellectual side of things, but also the raw side, the so-called 'dirty' side of things?

Alistair: I suppose yes you could say, that some of these sides tend to come to the fore more at particular moments more than other sides, but what interests me as a researcher also is which side to focus on. Merel: I have always had the impression with Truus, but also with other students, that whatever you are going through, there are always multiple parallel processes going on at the same time and you can't capture these completely but you might gain some access to some, but only if you study this on a very small scale, as opposed to large studies of patient experience.

Auto-ethnography is a way to acknowledge the many sides of the illness experience, both public and private, and to make them visible and known. This is a practice that honors people as capable; for example the first author's ability to function well as an assistant professor despite his illness. Simultaneously, such a practice also respects people as vulnerable beings, with everyday difficulties such as anxiety about the presence of blood in their stools or explaining to others what it means to live with the disease. They may include raw images of vomit and excrement that are rarely spoken about in connection with the first person, thereby putting the actual materiality of being ill in the foreground, rather than confining it to a (sanitized) medical discourse.

Being ill includes a bodily vulnerability, but also, as the above fragment illustrates, a social vulnerability (Schües, 2014). Social vulnerability refers to the potential of being judged by others, for example when the first author reflects on his capacity to contribute (intelligently and coherently) even though he is in the midst of an inflammation of his disease. Besides this social vulnerability, a person with a chronic illness or disability also runs the risk of being institutionally vulnerable. The first author could, for example, lose his job because people cannot understand the fact that he is capable of certain contributions (sharing his thoughts) but not of others (lecturing to a class). The image of a capable, able-bodied, thinking subject no longer works as an image of what it means to be (a caring and cared for) human. The fragment shows that we should produce more suitable, multiple images that honor both the capabilities and the vulnerabilities of people with chronic disease and disability, rather than viewing these dichotomously. We strongly believe that auto-ethnography has the potential to do exactly that.

\section{Conclusion}

The relatively young discipline of care ethics has alerted us to the need to reflect on care as practices of care, with a particular emphasis on interdependence, on relations 
as the locus of discovery of what is good (or humane), and on the particular good of people within a particular context. Care ethics does not depart from a specific norm or principle of (what ought to be) good care, because it does not conceive of good care as something static or a-historical (cf. Hertogh, 2010; Mol et al., 2010) and because the ethical content of practices might itself be comprehended as 'a way to be normative' (Willems \& Pols, 2010, p. 163). In fact, the supposedly neutral practice of ethical and moral reasoning as such should not be conceived of as value free, but instead as context sensitive and serving multiple interests (Leget, 2013; Walker, 2007).

In line with this, auto-ethnography as a praxis of care critiques an individualization discourse which involves isolated selves, absolute truths or certainties, and a-historicity. In line with what Merton has termed 'sociological autobiography', which includes 'perspectives, ideas, concepts, findings, and analytical procedures to construct and interpret a narrative text that purports to tell one's own history within the larger history of one's times' (Merton, 1972, p. 18), auto-ethnography tries to focus on factors such as personal meaning, empathic connection and resonation in order to uncover stories about 'embodied struggles' (Ellis, 2013), while being responsive to ambiguity, complexity and difference(s).

Consequently, auto-ethnography has the potential to create space for topics to which access is difficult and to stimulate the emergence of a variety of creative (re)presentations through a mutual learning process. Of course, we are mindful of the potential pitfalls of autoethnography; for example, the discussion of very personal events can lead to a situation of great vulnerability. Also, auto-ethnography can be susceptible to too much introspection, leading even to (self-)obsession, whereby one's own role is given too much priority and there is not the adequate amount of critical reflection or rigor that should accompany sound (qualitative) research.

Nevertheless, we feel that auto-ethnography holds great promise not only in care inquiry and disability studies, but also beyond the specific fields of (academic) inquiry. After all, there is an 'untapped well of personal experience' among all our own colleagues (and students), friends and family. Developing a relational autoethnography on illness or disability, with its unique combination of mutual reflection on the personal (evocative, literary and narrative) and attention to both capability and vulnerability, is not a question of 'capturing' a patient's voice or story. It is rather both a relational and caring practice itself which entails carefully handling vulnerabilities, listening, being attentive and responsive, and facilitating the exploration of valuable sociopolitical knowledge, whilst at the same time co-creating a fuller picture of someone who is faced with illness or disability, but defined beyond their perceived limitations.

\section{Acknowledgements}

The authors would like to thank Truus Teunissen and Silke Hoppe for their contributions during an earlier stage of this article.

\section{Conflict of Interests}

The authors declare no conflict of interests.

\section{References}

Agich, G. (2003). Dependence and autonomy in old age: An ethical framework for long term care. Cambridge: Cambridge University Press.

Denzin, N. (2014). Interpretive autoethnography. Los Angeles: Sage.

Ellingson, L., \& Ellis, C. (2008). Autoethnography as constructionist project. In J. A. Holstein \& J. F. Gubrium (Eds.), Handbook of constructionist research (pp. 445-466). New York: Guilford Press.

Ellis, C. (2004). The ethnographic I: A methodological novel about autoethnography. Walnut Creek: AltaMira Press.

Ellis, C. (2013). Crossing the rabbit hole. Autoethnographic life review. Qualitative Inquiry, 19(1), 35-45.

Frank, A. (2005). The remission society. In P. Conrad (Ed.), The sociology of health and illness (pp. 163-166). New York: Worth Publishers.

Gadamer, H. G. (1975). Truth and method. New York: Seabury Press.

Giddens, A. (1991). Modernity and self-identity: Self and society in the late modern age. Stanford: Stanford University Press.

Goodley, D., \& Runswick-Cole, K. (2016) Becoming dishuman: Thinking about the human through dis/ability. Discourse: Studies in the Cultural Politics of Education, 37(1), 1-15.

Guba, E., \& Lincoln, G. (1989). Fourth generation evaluation. Beverly Hills, CA: Sage.

Hertogh, C. M. P. M. (2010). De Senectute: Ethiek en kwetsbaarheid. Amsterdam: Vrije Universiteit.

Ho, A. (2008). The individualist model of autonomy and the challenge of disability. Bioethical Inquiry, 5, 193207.

Hooks, B. (1990). Marginality as a site of resistance. In R. Ferguson, M. Gever, T. T. Minh-ha, \& C. West (Eds.), Out there: Marginalization and contemporary cultures (pp. 241-243). Cambridge, MA: MIT Press.

Kittay, E. (2011). The ethics of care, dependence, and disability. Ratio Juris, 24(1), 4958.

Klaver, K., van Elst, E., \& Baart, A. J. (2014). Demarcation of the ethics of care as a discipline: Discussion article. Nursing Ethics. doi:10.1177/0969733013500162

Leget, C. J. W. (2013). Analyzing dignity: A perspective from the ethics of care. Medicine, Health Care and Philosophy, 16, 945-952.

Maréchal, G. (2010). Autoethnography. In A. J. Mills, 
G. Durepos \& E. Wiebe (Eds.), Encyclopedia of case study research (Vol. 2, pp. 43-45). Thousand Oaks, CA: Sage Publications.

Merton, R. K. (1972). Insiders and outsiders: A chapter in the sociology of knowledge. American Journal of Sociology, 78(1), 9-47.

Mol, A., Moser, I., \& Pols, A. J. (Eds.). (2010). Care in practice. On tinkering in clinics, homes and farms. Transcript-verlag: Bielefeld.

Neumann, M. (1996). Collecting ourselves at the end of the century. In C. Ellis \& A. Bochner (Eds.), Composing ethnography: Alternative forms of qualitative writing (pp. 172-198). Walnut Creek: Alta Mira.

Noddings, N. (1984). Caring: A feminine approach to ethics and moral education. Berkeley: University of California Press.

Nussbaum, M. C. (2006). Frontiers of justice. Cambridge, MA: Harvard University Press.

O’Toole, L. J., \& Meier, K. J. (2003). Plus ça change: Public management, personnel stability, and organizational performance. Journal of Public Administration Research and Theory, 13(1), 43-64.

Pols, J. (2013). The chronification of illness. An empirical ethics in care. (Inaugural lecture). Retrieved from www.oratiereeks.nl

Sayer, A. (2011). Why things matter to people: Social science, values and ethical life. Cambridge: Cambridge University Press.

Schües, C. (2014). Age and future. In S. Stoller (Ed.), Simone de Beauvoir's philosophy of age: Gender, ethics, and time (pp. 215-230). Berlin: De Gruyter.

Tronto, J. (1993). Moral boundaries: A political argument for an ethic of care. New York: Routledge.

Teunissen, G. J., Visse, M. A., \& Abma, T. A. (2015). Struggling Between Strength and Vulnerability, a patients' counter story. Health Care Analysis, 23(3), 288-305.

Visse, M. (2012). Openings for humanization in modern health care practices (PhD thesis). VU University, Amsterdam.

Visse, M., \& Niemeijer, A. R. (2016). Autoethnography as a praxis of care. The promises and pitfalls of autoethnography as a commitment to care. Qualitative Research Journal, 16(3), 301-312.

Walker, M. U. (2007). Moral understandings. A feminist study in ethics. London: Routledge.

Willems, D., \& Pols, J. (2010). Goodness! The empirical turn in health care ethics. Medische Antropologie, 22(1), 161-170.

\section{About the Author}

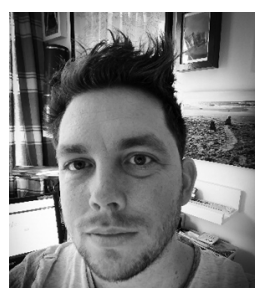

Alistair Niemeijer (PhD) works as an assistant professor in care ethics at the University of Humanistic Studies (Utrecht, NL) and as a post-doctoral researcher at the Vu University Medical Center (Amsterdam, NL). His PhD research has focused on the ethics of surveillance technology in long term care. Next to his autoethnographic pursuits, he currently supervises a multi-disciplinary research project on human dignity in public health policy.

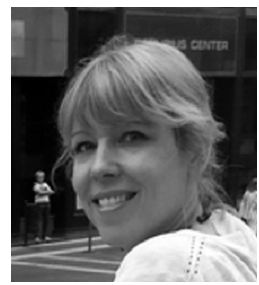

Merel Visse (PhD) is assistant professor and senior researcher at the University of Humanistic Studies, and combines rigorous scientific research with practical experimentation to foster practices of good care. She is an expert in responsive inquiry and evaluation approaches that nourish personal experiences and the unique histories of the people involved. Merel's work is carried out in many realms, always together with those whom it concerns: from hospitals and residential homes, to neighborhoods and family homes, with both non-profit and for-profit institutions. 